\title{
Genetic Variability in Glutamic Acid Decarboxylase Genes: Associations with Post-traumatic Seizures after Severe TBI
}

\author{
Shaun D. Darrah, \\ University of Pittsburgh Department of Physical Medicine \& Rehabilitation, 3471 Fifth Avenue, \\ Suite 202, Pittsburgh PA 15213. 412-692-4354 (fax). Darrah.shaun@medstudent.pitt.edu
}

Megan A. Miller, University of Pittsburgh Department of Physical Medicine \& Rehabilitation, 3471 Fifth Avenue, Suite 202, Pittsburgh PA 15213. 412-692-4354 (fax). millerm8@upmc.edu

Dianxu Ren, PhD, University of Pittsburgh School of Nursing, 3500 Victoria Street 440 Victoria Bldg, Pittsburgh, PA 15261.412-624-1201 (fax). dir8@pitt.edu

Nichole Z. Hoh, RN, PhD, University of Pittsburgh School of Nursing, 3500 Victoria Street 440 Victoria Bldg, Pittsburgh, PA 15261.412-624-8521 (fax).nmzst1@pitt.edu

Joelle Scanlon, PhD, University of Pittsburgh Department of Physical Medicine \& Rehabilitation, 3471 Fifth Avenue, Suite 202, Pittsburgh PA 15213. 412-692-4354 (fax). scanjm2@upmc.edu

Yvette P. Conley, PhD, and University of Pittsburgh School of Nursing, 3500 Victoria Street 440 Victoria Bldg, Pittsburgh, PA 15261. 412-624-8521 (fax). yconley@pitt.edu

\section{Amy K. Wagner, MD}

University of Pittsburgh Department of Physical Medicine \& Rehabilitation, 3471 Fifth Ave, Suite 201, Pittsburgh PA 15213. 412-692-4354 (fax) wagnerak@upmc.edu

\section{Abstract}

Post traumatic seizures (PTS) occur frequently after traumatic brain injury (TBI). Since gammaamino butyric acid (GABA) neurotransmission is central to excitotoxicity and seizure development across multiple models, we investigated how genetic variability for glutamic acid decarboxylase (GAD) influences risk for PTS. Using both a tagging and functional single nucleotide polymorphism (SNP) approach, we genotyped the GAD1 and GAD2 genes and linked them with PTS data, regarding time to first seizure, obtained for 257 adult subjects with severe TBI. No significant associations were found for GAD2. In the GAD1 gene, the tagging SNP (tSNP) rs3828275 was associated with an increased risk for PTS occurring <1wk. The tSNP rs769391and the functional SNP rs3791878 in the GAD1 gene were associated with increased PTS risk occurring $1 \mathrm{wk}-6 \mathrm{mo}$ post-injury. Both risk variants conferred an increased susceptibility to PTS compared to subjects with 0-1 risk variant. Also, those with haplotypes having both risk

\footnotetext{
(C) 2012 Elsevier B.V. All rights reserved.
}

Publisher's Disclaimer: This is a PDF file of an unedited manuscript that has been accepted for publication. As a service to our customers we are providing this early version of the manuscript. The manuscript will undergo copyediting, typesetting, and review of the resulting proof before it is published in its final citable form. Please note that during the production process errors may be discovered which could affect the content, and all legal disclaimers that apply to the journal pertain.

AUTHOR DISCLOSURE STATEMENT: No competing financial interests exist. 
variants had a higher PTS risk 1wk-6mo post-injury than those without these haplotypes. Similarly, diplotype analysis showed those with 2 copies of the haplotype containing both risk alleles were at the highest PTS risk. These results implicate genetic variability within the GABA system in modulating the development of PTS.

\section{Keywords}

Traumatic brain injury; seizures; GABA; glutamic acid decarboxylase; promoter; single nucleotide polymorphism

\subsection{INTRODUCTION}

A significant consequence following traumatic brain injury (TBI) is the development of post-traumatic seizures (PTS). Nearly $15 \%$ of hospitalized TBI patients with significant injuries develop seizures, and PTS accounts for $20 \%$ of symptomatic seizures and $5 \%$ of all seizures in the general population (Englander et al., 2003; Hauser et al., 1991). Individuals with more severe brain injuries have higher risk for PTS compared to those with mild injuries, and they often have a prolonged period of time in which they are at risk of developing PTS (Yablon and Dostrow, 2001). Also, time to first seizure can occur up to years post injury (Raymont et al., 2010; Swartz et al., 2006). Patients who suffer from PTS can have a significantly reduced quality of life (Liu et al., 2011). Of patients who experience one PTS, 86\% will have a second within 2 years (Haltiner et al., 1997). The development of seizures is a clinically significant phenomenon, as prolonged convulsive seizures can be detrimental to the brain, and non-convulsive seizures can have adverse outcomes (Chen and Wasterlain, 2006; Young et al., 1996). Bao et al. have shown that an induced period of posttraumatic seizures significantly exacerbates the structural damage caused by TBI in rats (Bao et al., 2011).

Although PTS is common after TBI, the neurobiological underpinnings associated with it are not well understood. A common linkage between the pathophysiology associated with secondary TBI and seizure susceptibility is the gamma-aminobutyric acid (GABA) neurotransmission system. GABA is a primary inhibitory neurotransmitter in the brain, and under physiological conditions, modulates excitatory tone. GABA is synthesized from glutamate by the enzyme glutamic acid decarboxylase (GAD). The mature GAD protein has two forms; GAD67 is coded by the GAD1 gene and GAD65 is coded by the GAD2 gene, both of which are responsible for catalyzing the production of GABA from Glutamate in the brain (Kuo et al., 2009). GAD1 maps to chromosome 2q31, while GAD2 maps to 10p11 (Bu et al., 1992; Online Mendelian Inheritance in Man, 2011).

The GABAergic system has been implicated as a mediator of seizure activity. Changes in GABA transporter activity have been closely related to both the pathology and treatment of epileptic seizures (Allen et al., 2004). Drugs which enhance CNS GABAergic neurotransmission can be clinically effective for the treatment of epilepsy (Meldrum, 1989). Furthermore, low CSF GABA concentrations are observed in a variety of epileptic syndromes, including genetic models of epilepsy (Hasegawa et al., 2004; Ellenberger et al., 2004; Treiman, 2001). Rodent studies have shown that levels of GAD67 mRNA and protein are enhanced in granule cells/mossy fibers after sustained epileptic seizures (Schwarzer and Sperk, 1995; Sperk et al., 2003). Further, another study showed increased GAD67 levels in the granule cells/mossy fibers in patients with temporal lobe epilepsy as compared to postmortem controls (Sperk et al., 2011). These findings support the idea that the increased levels of GAD67 could also represent a defense mechanism to combat the development of PTS. 
GABAergic neurotransmission impacts TBI pathophysiology in several ways acutely after injury. For example, increased extracellular GABA, in conjunction with increased extracellular glutamate, has been documented following TBI (Nillson et al., 1990; Kanthan and Shuaib, 1995). Increased GABA levels may represent a compensatory mechanism to combat excitotoxicity and early seizure activity in the injured brain. However, a study in rodents showed a $26 \%$ decrease in GAD positive neurons in the cerebral cortex following fluid percussion injury (Neese, et al., 2006). GABA-A receptors are implicated with in vitro models as modulators of excitotoxic injury (Muir et al., 1996), and manipulation of GABAA receptors, during the acute and chronic phases of experimental TBI, can influence behavioral outcomes (O’Dell et al., 2000).

Although studies suggest that genetic susceptibility contributes to the development of seizure disorders (Cavalleri et al., 2007; Jamali et al. 2010) and treatment response (Ebid 2007; Hung et al., 2005; Kwan et al., 2007), little has been studied in the area of genetic susceptibility to PTS. Previous work in our lab has shown that genetic variation in the adenosine A1 receptor is associated with susceptibility to PTS (Wagner et al. 2010). Studies involving the APOE gene have been mixed, with some showing that carriage of the apolipoprotein 4 (APOE4) allele increases the risk for the development of late PTS (DiazArrastia et al., 2003), while others do not show a clear association (Miller et al., 2010; Anderson et al., 2009). Recent work suggests that variation in the gene encoding methylenetetrahydrofolate reductase (MTHFR) contributes to risk for post-traumatic epilepsy in a military population (Scher et al., 2011). Thus, genetic variation represents a largely unexplored, yet potentially useful, area of research to determine PTS susceptibility.

Given that GABAergic neurotransmission can influence excitotoxicity and seizure development, the goal of this study was to determine if genetic variability within the GAD1 and GAD2 genes was associated with the development of PTS in a human population with severe TBI. This study utilized both tagging and functional single nucleotide polymorphisms (SNPs) to screen the GAD1 and GAD2 genes for associations with PTS within <1wk, $1 \mathrm{wk}-6 \mathrm{mo}$, and beyond $6 \mathrm{mo}$ post-injury.

After accounting for mortality, univariate, multivariate, and haplotype analyses suggest a significant association between risk for PTS occurring $1 \mathrm{wk}-6 \mathrm{mo}$ post injury and the presence of both the functional SNP rs3791878 and the tagging SNP rs769391.

Additionally, the tagging SNP rs 3828725 was associated with PTS $<1$ wk post injury. These findings may have implications for PTS risk stratification and individualized treatment strategies for persons with TBI.

\subsection{METHODS}

\subsection{Study Design and Subjects}

This study was approved by our Institutional Review Board. 257 adults with severe TBI, enrolled between 2000 and 2008, were genotyped for the GAD1 and GAD 2 genes as part of a study evaluation of genetic associations and outcome. There is substantial evidence from dbSNP (http://www.ncbi.nlm.nih.gov/projects/SNP) that several SNPs included in this study have significant allele frequency differences by ancestral background. As such, subjects included in this study were limited Caucasians. Other inclusion criteria included age ranging from the ages of 16-75, severe TBI (GCS score of <8), evidence of TBI (intracranial injury) on CT scan, and had an extraventricular drain in place to monitor intracranial pressure. Subjects were excluded from the study if they had documented evidence of penetrating head injury, prolonged cardiac or respiratory arrest (greater than 30 minutes). Subjects were also excluded if they were less than 6 months removed from their injury, had a premorbid history of seizures, and were not Caucasian. 


\subsection{Critical Care Management}

All subjects enrolled presented for care at one of our level 1 trauma centers, with 24 hour neurosurgery, trauma surgery and critical care services available. Subjects were admitted to the neurotrauma intensive care unit and received treatment consistent with The Guidelines for the Management of Severe Head Injury (Brain Trauma Foundation et al., 2007). Standard electroencephalography was ordered intermittently for subjects where there was clinical suspicion of PTS activity, including non-convulsive seizures. In general, subjects with severe injuries received PTS prophylaxis for 1 week based on previously published studies (Temkin et al., 1990). Temperature was monitored regularly, and a subset of subjects received moderate hypothermia as a part of clinical care or if they were enrolled in a randomized controlled clinical trial evaluating moderate hypothermia after severe TBI. As a part of the study subjects were brought to a target temperature of 32.5-33.5 degrees Celsius with 48 hours of cooling with passive rewarming. There were 52 individuals that received hypothermia. Subjects not receiving hypothermia were treated to maintain a normothermic state.

\subsection{Demographic and Injury Data}

Information regarding the subject's age, gender, and race were abstracted from the medical records. The length of hospital stay, cranial surgeries to treat a TBI lesion (in addition to the burr hole procedure for EVD placement), mechanism of injury, hypothermia status, and GCS scores were also abstracted. Initial hospital GCS scores were recorded for each subject within 8 hours of injury and after resuscitation and without the influence of paralytics.

Patients having undergone intubation by the time of this GCS assessment received a score of 1 for the verbal scale of the GCS. Information about administration of anti-epileptic drugs (AEDs) during their acute hospital stay was also noted. Common AEDs, used at our center for seizure prophylaxis, or treatment were included in the analysis. Drugs with anticonvulsant properties that were explicitly designated in the medical record for use in treating a condition other than seizure treatment/prophylaxis, were excluded from analysis. Head CT findings about injury type were abstracted from the medical record, and the presence versus absence of each injury type was assessed. Injury types included subdural hematoma (SDH), epidural hematoma (EDH), contusion, Subarachnoid hemorrhage (SAH), intraventricular hemorrhage (IVH), intracerebral hemorrhage (ICH), diffuse axonal injury (DAI), and "other lesions". Also, the number of injury types was summed for each subject evaluated for associations with PTS.

\subsection{Seizure Assessment}

Information about PTS was collected through electronic medical records available from the acute hospitalization as well as any inpatient rehabilitation and outpatient clinic notes for care provided within our health system. Data abstraction was supervised by a TBI rehabilitation specialist involved with the study. Time to first seizure was the primary measure abstracted. Inpatient notes used to determine time to first seizure included ambulance emergency room reports, progress notes, nursing notes, clinical EEG study reports from staff epilepsy specialists, patient history and physical reports, and discharge or transfer summaries. Notation in medical records referring to convulsions, seizures, status epilepticus or seizure disorder was taken as PTS occurrence for an individual. If a notation to possible seizure activity were ambiguous or unclear, that notation was classified as a "no seizure" occurrence. Last available records found for the cohort ranged from 6 months post injury to 8 years post injury. Determining PTS onset for time frames spanning beyond initial acute care hospitalization required at least one discharge/death summary or inpatient/ outpatient note related to the TBI and referencing the appropriate PTS period. 
Inherent to the data abstraction approach described for this study, specific dates for time to first seizure were not uniformly available for all subjects. Thus a discrete survival analysis approach, using time based categories for seizure onset and adjusted for mortality within those time based categories, was used. Although clinically it is not known a priori if first PTS onset will occur days versus years after injury, the literature suggests that pathology for early and later PTS includes different risk factors (Haltiner 1997, Temkin 2003). Thus, we felt it most appropriate to define a time specific no seizure group for each time based PTS cohort assessed. Time to first documented seizure was categorized as occurring within three different time based categories representing the acute, sub-acute, and chronic phases of TBI recovery. Categories include 1) <1wk after TBI 2) 1 wk-6mo post injury, and 3) at least $6 \mathrm{mo.}$ post-injury. The acute category, and the sub-acute+chronic categories, follow published definitions early and late PTS respectively (Temkin et al., 1990). Subjects who died within the first week, but did not seize, were removed from early PTS analysis in order to eliminate mortality as a bias regarding seizure rates. Those who died and did not seize within the first 6 mos were removed from seizure analyses assessing risk for PTS $1 \mathrm{wk}-6 \mathrm{mo}$, and those who died at any point and did not seize were removed from seizure analyses assessing PTS risk at $>6$ mo.

\subsection{Outcome Measures}

An outcome assessment battery was also collected for each subject at six months post injury that included the Glasgow Outcome Scale (GOS) score. The GOS is commonly used as a global outcome measure in TBI (Jennet and Bond 1975) that also includes the collection of information regarding seizures. GOS associations with SNPs in each cohort were examined. To appropriately account for mortality in PTS analysis, death date was recorded and coded in the same way as PTS. Death was recorded as occurring 1) $<1 \mathrm{wk}$ post-TBI 2) $1 \mathrm{wk}-6 \mathrm{mo}$ or 3 ) beyond $6 \mathrm{mo}$ after TBI. Mortality was collected using death reports in medical records as well as the social security death index online (Rootsweb, 2011)

\subsection{Single Nucleotide Polymorphism Selection}

tSNPs with a minor allele frequency of at least $20 \%$ were selected based on data from the HapMap database (International HapMap Project: http://snp.cshl.org/) and SNP database (dbSNP: http://www.ncbi.nlm.nih.gov/projects/SNP). At the time of selection, these tSNPs captured the variability of the gene including 1000 bases $5^{\prime}$ upstream into the promoter region, which is based on data from build 36 . We evaluated each tSNP for allelic, genotype and grouped genotype as independent variables for associations with PTS and outcome. The two groupings used were presence of variant (homozygous variant and heterozygotes combined) versus homozygous wild type and presence of wild type (homozygous wild type and heterozygotes combined) versus homozygous variant (see Table 2).

\subsection{DNA Extraction and Genotyping Methods}

DNA was extracted from one of two sources for each subject, whole blood collected prior to transfusion or cerebrospinal fluid (CSF). Whole blood was collected into EDTA vacutainer tubes, processed to retrieve the buffy coat and DNA extracted using a simple salting out procedure (Miller et al., 1988). CSF was collected by passive drainage as standard of care, and DNA was extracted using the Qiamp DNA extraction protocol for extraction from body fluids (Qiagen Corporation, Valencia, CA).

Tagging SNPs rs7073119 and rs3828275 as well as functional SNP rs3791878 were genotyped using $5^{\prime}$ exonuclease Assay-on-Demand TaqMan assays (Applied Biosystems Incorporated, Foster City, CA). Amplification and genotype assignments were conducted using the AB17000 and SDS 2.0 software (Applied Biosystems Incorporated, Foster City, CA). Double-masked genotype assignments were made for each SNP, they were compared, 
and each discrepancy was addressed using raw data or re-genotyping. The remaining SNPs (rs769391, rs3749034, rs3791860, rs4668237) were genotyped using iPLEX Gold SNP Assay (Sequenom Inc., San Diego, CA). The iPLEX Gold SNP assays included blind duplicates for quality assessment. Genotyping methods failed for a few subjects for each of the SNPs as outlined below: rs769391: $n=6$ (2.3\%); rs3749034: $n=29$ (11.3\%); rs3791860: $\mathrm{n}=9$ (3.5\%); rs4668237: $\mathrm{n}=13$ (5.1\%); rs7073119: $\mathrm{n}=42$ (16.3\%); rs3828275: $\mathrm{n}=27$ (10.5\%); rs3791878: $\mathrm{n}=15(5.8 \%)$.

\subsection{Haplotyping}

For the GAD1 gene, we used PHASE software (Stephens et al., 2001) to generate the most likely haplotypes (and haplotype pairs, or diplotypes) for each individual in this unrelated cohort using 6 tSNPs. A total of 17 haplotypes were generated, with a frequency high enough to occur in at least subject present in our population. Both the presence of a specific haplotype and diplotypes, were analyzed at all time points.

In preliminary analysis, all haplotypes were used to assess risk for PTS occurrence $<1 \mathrm{wk}$ after injury, between 1wk-6mo after injury, and for PTS occurrence beginning at least $6 \mathrm{mo}$ after injury. Subsequently, for data reduction and targeted analysis of haplotypes, only those haplotypes having either the presence or absence of informative variant(s) from the single SNP analysis at a given time point were then conducted. Haplotype assessment for PTS $<1 \mathrm{wk}$ involved comparisons of haplotypes with versus without SNPs significant for PTS risk in univariate analysis. Haplotype assessment for PTS 1wk-6mo involved the comparisons of haplotypes with versus without SNPs significant for PTS onset within this time frame in univariate analysis.

For PTS occurrence 1wk-6mo post-injury, individuals carrying haplotypes containing all risk alleles for GAD1 were compared to those that did not have all risk alleles present in the haplotype. Analysis was then conducted to assess PTS risk for those having both risk haplotypes in a dosage dependent manner (i.e. individuals having 2,1 , or 0 haplotypes with all risk alleles). Diplotype analysis (i.e. haplotype pair analysis) was then conducted where 1) individuals having at least one haplotype with all risk variants were compared to those with a haplotype that had no risk variants, and 2) Individuals having haplotype pairs with either zero or one haplotype containing all risk variants were compared to those having a haplotype pair where each haplotype contains all risk variants.

\subsection{Statistical Analysis}

Summary statistics for this cohort included means, standard error of the mean (SEM), medians, and frequencies were computed. Independent t-tests were used to assess differences among PTS groups for continuous variables. Chi square analyses or the Fisher's exact test when appropriate, were used to explore significant associations between GAD genotype and descriptive variables like GOS and mortality. Genotype associations with PTS were evaluated using a discrete survival analysis approach, such that subjects within each "time to first PTS category" were compared to those without PTS at any time point. Chi square, with Fisher's exact test as appropriate, was also performed to compare individual GAD genotypes to PTS. Similar approaches were taken for haplotype and diplotype analyses.

tSNPs with at least one significant univariate association ( $p \unlhd 0.05)$ within a PTS time interval were then further evaluated using multivariate logistic regression analyses within that time interval to determine adjusted relationships between the tSNP of interest and PTS. Covariates tested were those that were associated in univariate analysis with PTS $(p<0.10)$. Clinically relevant covariates (e.g. age, GCS, gender) were also included in the multivariate 
model, regardless of univariate results. Multiple risk genotypes associated with PTS were then assessed in the same multivariate model (i.e. multi-variant analysis) using the same covariate structure. Due to small numbers in some categories, covariatexgenotype interactions with PTS were not explored in regression analyses.

To avoid the confounding factor of death on seizure incidence, we removed subjects from analysis who died within a week of injury and did not seize when comparing GAD genotypes and alleles to PTS within this time frame ( $\mathrm{n}=32$ deceased within 1wk). All documented deceased subjects, except one subject with PTS occurring after one week, were removed to assess GAD associations with PTS between 1wk-6mo, as well as for PTS first occurring after 6 mo post-TBI ( $\mathrm{n}=27$ deceased $1 \mathrm{wk}$ to 6 mos, $\mathrm{n}=3$ deceased after 6 mos). Thus the population size for assessing seizures within $1 \mathrm{wk}$ was $\mathrm{n}=192$, seizures $1 \mathrm{wk}-6$ mos. was $n=163$, and seizures after 6 months was $n=161$. Mortality associations with genotype were also assessed.

\subsection{RESULTS}

\subsection{Study Population}

Of the 257 subjects included for final analysis, 201 were male, and 56 were female. The median Glasgow Coma Scale (GCS) score was 6, and the mean age was $35.43 \pm 0.958$ years. Approximately $19.8 \%$ of subjects had documented evidence in their medical records of PTS. Out of the entire population, $95.7 \%$ of subjects were given AED within their acute hospital stay.

Subjects in the cohort were then defined by the time of first seizure, and each subject who seized was only counted once. Of those that seized $(n=51), 18$ occurred $<1$ wk of injury, 16 occurred $1 \mathrm{wk}-6 \mathrm{mo}$, and 17 occurred beyond $6 \mathrm{mo}$. The length of acute hospital stay ranged from less than a day to 61 days post-injury and did not significantly differ between PTS groups. For the cohort $(n=257)$, the mortality rate for the $<1 \mathrm{wk}$ PTS cohort was $12.5 \%$, and it was $12 \%$ for the cohort in which seizures occurring 1 wk-6mo after TBI were analyzed. There were no significant associations between mortality within each cohort or with genotypes significantly associated with PTS in that cohort. Additionally, there were no GAD SNP associations with GOS scores taken at 6 mos. among survivors. Table 1 further describes general demographic and characteristics for those within each PTS analysis cohort, including the percentages of each cohort with various types of injury based on CT analysis. Notably, cranial surgery to treat a TBI specific lesion was significantly associated with the cohort for $1 \mathrm{wk}-6 \mathrm{mo}$ PTS analysis, and the cohort for PTS occurring beyond $6 \mathrm{mos}$. SDH was associated with PTS $<1 \mathrm{wk}$ as well as PTS $>6 \mathrm{mos}$. However, there were no associations with the total number of injury types, based on CT analysis, with regard to PTS risk in any of our cohorts.

\subsection{Evaluation of SNPs}

Known functional and tagging SNPs for the GAD1 and GAD2 genes were evaluated for association with PTS (Table 2). For the GAD1 gene, the tagging SNP rs3828725 homozygous wild-type genotype was associated with PTS $<1 \mathrm{wk}(\mathrm{p}=0.019)$. Additionally, the homozygous wild-type genotype was associated with PTS between 1wk-6mo for both the functional SNP rs3791878 ( $\mathrm{p}=0.014)$ and the tagging SNP rs769391 ( $\mathrm{p}=0.036)$. All other SNPs evaluated for GAD1 and GAD2 were not associated with PTS activity. All SNPs were in Hardy-Weinberg equilibrium, indicating that the expected proportion of genotypes in this population was obtained. 


\section{3 rs3828275 association with PTS occurring $<1$ wk after TBI}

When evaluating rs 3828275 , PTS $<1 \mathrm{wk}$ after TBI occurred in $2.99 \%$ of individuals with the CC genotype, $12.16 \%$ of individuals with the CT genotype, and $20 \%$ of individuals with the TT genotype, which was statistically significant $(\mathrm{p}=0.014)$ (Figure 1). Further, grouped genotype analysis showed differences $(\mathrm{p}=0.019)$ between subjects with the $\mathrm{CC}$ genotype (protection genotype) and those with either the CT or TT genotype. Also, a trend was noted with PTS rates when subjects with the TT genotype was assigned as the risk genotype and compared to those with the CT and CC genotypes ( $\mathrm{p}=0.055)$ (Table 2). Multivariate analysis showed that, after adjusting for age, gender, GCS score, subdural hematoma, and neurosurgical intervention, subjects with the $\mathrm{CC}$ genotype had significantly higher odds $(\mathrm{OR}=5.601$; CI 1.211-25.908; $\mathrm{p}=0.028)$ of not having PTS compared to those with either the $\mathrm{CT}$ or TT genotype (Table 3). Multivariate models built comparing $\mathrm{CC}+\mathrm{CT}$ vs. TT showed a trend for higher PTS in those with the TT genotype ( $\mathrm{P}=0.07)$ (Model not shown). Multivariate genotype analysis for TT vs. CT vs. CC showed those TT vs. CC genotypes had higher odds of PTS ( $\mathrm{p}=0.0175$ ), while CT vs. CC genotypes tended to have higher PTS rates $(\mathrm{p}=0.0595)$ in the early period (Model not shown).

\section{4 rs3791878 associations with PTS 1wk-6mo after TBI}

When assessing the proportion of subjects with each genotype for rs3791878 and PTS development between $1 \mathrm{wk}-6 \mathrm{mo}, 16 \%$ of the population with the homozygous wild type (GG) genotype had evidence of PTS, while only $5 \%$ of those with the GT genotype and no subjects with the TT genotype had PTS, ( $\mathrm{p}=0.05)$ (Figure 2a). Further, grouped genotype analysis showed a significant difference $(\mathrm{p}=0.014)$ between subjects with the $\mathrm{GG}$ genotype (risk genotype) and those with either the GT or TT genotype with regard to PTS over this time frame. (Table 2). Multivariate analysis showed that, after adjusting for age, gender, GCS score, and neurosurgical intervention, subjects with the GG genotype had significantly higher odds (OR=4.892; CI 1.244-19.246; $\mathrm{p}=0.0231)$ of developing PTS compared to those with either the GT or TT genotype (Table 4a).

\section{5 rs769391 associations with PTS between 1wk-6mo after TBI}

In addition to rs3791878, genotype differences were also noted for the tagging SNP rs769391 PTS occurring between $1 w k-6 m o$ after TBI. Figure $2 b$ shows that $14.6 \%$ of subjects with the AA genotype had PTS activity, while $3.7 \%$ of those with the AG genotype and $6.25 \%$ of those with the GG genotype had PTS activity ( $\mathrm{p}=0.09$ ). There was a significant difference $(\mathrm{p}=0.036)$ between subjects with the AA genotype (risk genotype) and those with either the AG or GG genotype with regard to PTS during this period (Table 2). No significant associations were noted with PTS when subjects with a GG genotype were assigned as the risk genotype group and compared to those with the AG and AA genotypes $(\mathrm{p}=1.00)$. Multivariate analysis showed that after adjusting for age, gender, GCS score, and neurosurgical intervention, subjects with the AA genotype had significantly higher odds (OR=3.747; CI 0.952-14.748; $\mathrm{p}=0.058$ ) of developing PTS compared to those with either the AG or GG genotype (Table 4b).

\subsection{Multi-variant associations with PTS between 1wk-6mo after TBI}

Based on the analyses above, the risk variants for PTS 1wk-6mo post injury were defined as the homozygous wild type for both rs3791878 (GG) and rs769391 (AA). We then assessed if there was a cumulative risk associated with having an increased number of risk variants. Comparison of PTS activity between individuals with zero, one, or both risk variants showed a significant difference between groups, where those with 2 risk variants had higher PTS frequencies than those with 1 or 0 risk variants $(\mathrm{p}=0.019)$ (Figure 2c). Multivariate analysis comparing individuals with 2 risk variants versus those with no risk variant showed 
a significantly higher odds $(\mathrm{OR}=6.568$; CI 1.285-33.580; $\mathrm{p}=0.024)$ of developing PTS $1 \mathrm{wk}-6 \mathrm{mo}$ from injury (Table 5). There were no significant differences in the multivariate analysis when comparing individuals with 1 risk variant to those with no risk variant or those with both risk variants.

\subsection{Haplotype Analysis}

When assessing haplotypes for the population with PTS within the first week post-TBI, 64\% of the haplotypes carried the risk variant (T) for rs3828275, and 19\% of diplotypes (haplotype pairs) were homozygous for the risk variant SNP. No significant associations were found when comparing all haplotypes and PTS occurrence < $1 \mathrm{wk}$ after injury. Similiarly, chi square analysis showed no associations with haplotype pairs carrying the risk variant, versus those haplotypes without the risk variant.

When assessing haplotypes for our population with seizures $1 \mathrm{wk}-6 \mathrm{mo}$ post injury, $62.6 \%$ of the haplotypes carried both of the GAD1 risk alleles (rs3791878 and rs769391) and 42.4\% of diplotypes (haplotype pairs) contained haplotypes carrying both GAD1 SNP risk alleles. No significant associations were found when comparing all haplotypes and PTS occurrence 1 wk-6mo post injury. However, grouped haplotype and diplotype analysis revealed common trends for PTS occurring 1wk-6mo post injury. Chi-square analysis for haplotypes showed that those with haplotypes containing both risk variants had a higher PTS frequency than those with haplotypes having only 0 or 1 risk variant within the haplotype $(\mathrm{p}=0.033)$ (Figure 3a). Analysis comparing dosage of risk haplotype (2, 1 or 0 of the haplotypes carrying both risk alleles) via diplotype analysis showed that individuals carrying two risk haplotypes had a significantly higher percentage of PTS at $1 \mathrm{wk}-6 \mathrm{mo}$ post injury compared to those who had either 1 or 0 risk haplotypes $(\mathrm{p}=0.038$ ). (Figure $3 \mathrm{~b}$ ) Grouped diplotype (haplotype pair) analysis confirmed this finding by showing a significant association with haplotype pairs, where those with both haplo-pairs containing both risk variants had a higher seizure rate than those who did not ( $\mathrm{p}=0.015$ ) (figure $3 \mathrm{c}$ ).

\subsection{DISCUSSION}

While clinical risk factors for PTS have been fairly well characterized, not every patient with clinical risk factors develops PTS. Variability in seizure occurrence may be attributable to the unique genetic makeup that each patient brings to post-TBI recovery. Work in our lab has identified that genetic variation in the Adenosine A1 receptor is associated with increased susceptibility to PTS within the first week as well as PTS beyond the first week after TBI (Wagner et al., 2010). Adenosine, like GABA, is a major neuroinhibitory molecule, and thus, exploring candidate genes within the GABAergic system for associations with PTS is a logical targeted genetic screening approach.

In our study, both functional and tagging SNPs for the GAD1 gene were explored for PTS within <1wk, 1wk-6mo, and beyond 6mo post injury. The tagging SNP for the GAD1 gene, rs3828275, was linked to an increased risk for PTS $<1 \mathrm{wk}$. There appears to be a dosing phenomenon with these alleles. Risk for PTS $<1 \mathrm{wk}$. PTS $<1 \mathrm{wk}$ occurred in $2.99 \%$ of individuals with the CC genotype, $12.16 \%$ of individuals with the CT genotype, and $20 \%$ of individuals with the TT genotype and significant/near significant comparisons noted for genotype as well as both variants in univariate and multivariate models. For functional SNP rs3791878 (GG genotype) and the tagging SNP rs769391 (AA genotype), there was a significant association with PTS 1wk-6 mo in both univariate and multivariate logistic regression. These SNPs also were related to PTS in haplotype and diplotype analyses. To our knowledge, this is the first clinical research report implicating genetic variability within the GAD1 gene in the development of either non-traumatic seizures or PTS. 
The effects on GAD activity are not known for rs 3791878. However, its location in the 5' flanking region (containing the promoter) suggests that polymorphisms in this region may affect transcription of the gene. The $\mathrm{G}$ to T nucleotide change that occurs with rs3791878 appears to result in loss of the aryl hydrocarbon receptor nuclear translocator (ARNT) and xbox binding protein 1 (XBP1) transcription sites within the promoter region (Du et al., 2008), providing a potential mechanism for this significant association. ARNT and XBP1 are transcription factors influencing the expression of many types of genes including genes involved with immune and cellular stress response. (Yoshida et al., 2006; Ruegg et al., 2008) While the exact functionality associated with tagging SNPs rs769391 and rs3828275 are not known, it is apparent that the portions of DNA tagged by them are relevant to PTS. Isolation of the DNA block housing these variants, and subsequent DNA sequencing, may be required to learn more about the role these variants represent in terms of PTS risk and pathology.

Similar PTS rates were noted for each risk variant associated with PTS between 1wk-6mo. post-TBI (rs3791878 and rs769391). Interestingly, multi-variant analysis showed that having both variants was linked to higher PTS rates compared either one or zero, yet having both variants was associated with a PTS frequency similar to those observed when assessing either risk variant alone. These results suggest that individuals must have both risk polymorphisms in order to have an increased risk for PTS onset during this time period. The majority of possible haplotypes for the GAD1 gene (62.6\%) contained both polymorphisms identified through single SNP analysis, and haplotype analysis confirmed the multi-variant analyses by showing that the risk polymorphisms were only associated with PTS risk when located on the same haplotype (cis-conformation) with each other, indicating that two potential changes in gene function and/or gene product are required compared to one or the other alone. Diplotype and grouped diplotype analysis also showed similar seizure rates compared to multi-variant analyses, suggesting that those with haplotype pairs both containing a risk allele with both risk variants are the subjects who are at increased risk for PTS during this time period.

The two risk SNPs for the 1wk-6mo analysis are located on either end of the gene (rs3791878 near Exon 1 and the promoter region, and rs769391 is between exons 13 and 14) (Bu \& Tobin, 1994; Bu et al., 1992). Since more than one SNP was associated with PTS $1 \mathrm{wk}-6 \mathrm{mo}$, assessing SNP, haplotype, and diplotype associations provides complementary information from which to develop new hypotheses and further explore the nature of these genetic associations from a neurobiological perspective. One possible hypothesis is that having an allele with a given SNP that is associated with seizures, as well as grouped haplotype and diplotypes containing the risk alleles for PTS from more than one SNP, suggests that there may be a risk variant, (potentially a rare variant), located within the region spanning the SNPs that accounts for the association. Intervening tSNPs are not associated with PTS, leading us to hypothesize that $\mathrm{LD}$ as a reason for these associations specifically is less likely. Yet data from the hapmap database (http://snp.cshl.org/) indicates that these SNPs have a pair-wise comparison r-square value of 0.536. As such, further study, using larger sample sizes will be required to definitively determine if/how the intervening region between these tSNPs is implicated with regard to PTS risk. Also, it is notable that the GAD protein can be membrane bound in synaptic vesicles, using heat-shock protein 70 as an anchoring protein, and membrane bound GAD is thought to facilitate an efficient process for synthesis and vesicular packaging of GABA (Hsu et al., 2000). Studies in brain show that membrane bound GAD is present as a homodimer (Nathan et al., 1994a, 1994b). Thus, another neurobiological implication of the findings in hand in relation to PTS risk may be that diplotypes with each of the risk alleles creates a homogenous pool of GAD protein that is somehow less functional, perhaps as a homodimer in vesicular membranes, with facilitating GABA synthesis and/or packaging. 
GAD1 gene variation associations with PTS occurred early, in the first week post-TBI, and between the first week and six months post-injury. Our previous work also suggests differences in timing of first onset of PTS with regard to genetic susceptibility loci for adenosine A1 receptor gene (Wagner et al., 2010). For GAD1, associations with early PTS $(<1 \mathrm{wk})$ may be due to GABAergic modulation of acute excitotoxicity that is known to occur acutely after TBI (Neese et al., 2006; Muir et al., 1996; O'Dell et al., 2000, Wagner et al., 2005; Ruppel et al., 2001; Palmer et al., 1993). Genetic susceptibility over the sub-acute phases of TBI recovery (1wk-6mo) may reflect the ongoing evolution-resolution of many components of the injury response, including epigenetic modifications that are known to occur in the setting of TBI (Gao et al., 2006; Zhang et al., 2007) and environmental manipulation (Sweatt 2009; Covic et al. 2010).

We also explored a tSNP for the GAD2 gene, which codes for the enzyme GAD65 on chromosome 10p11.23 (Kuo et al., 2009). GAD65 is primarily involved in synaptosomal GABA release, and can be activated rapidly when there is a demand for GABA (Soghomonian and Martin, 1998). GAD65 can mediate activity-dependent GABA synthesis invoked by seizures in rats (Patel et al., 2006). We used tSNP rs7073119 as a marker for variability in the GAD2 gene. There were no significant findings between rs7073119 and PTS activity. However, given the association of GAD2 variability with seizure activity and diminished response to GABAergic drugs (Asada et al., 1997; Kash et al., 1999), future identification and analysis of a wider variety of tSNPs for GAD2 may be of value to better characterize the gene.

We examined several variables within our PTS cohorts, and of the variables explored, only cranial surgery was linked to PTS. Individuals who underwent cranial surgery to treat a specific intracranial lesion were more likely to seize in the $1 \mathrm{wk}-6 \mathrm{mo}$ and beyond $6 \mathrm{mo}$ periods. This association with PTS held up in multivariate analyses for the $1 \mathrm{wk}$ to $6 \mathrm{mo}$ cohort, which is consistent with our previous work (Wagner et al. 2010). Recent findings show glial scarring associated with cranial surgery can increase PTS rates after TBI (Lin et al., 2009). Interestingly, SDH was a significant variable influencing PTS risk with both early and late risk. The fact that many patients with SDH often need surgery to decompress the lesion may be one reason for this association. Other studies (Temkin et al. 2003) confirm that SDH can be a risk factor for PTS.

Similar to our previous work (Wagner et al. 2010), gender, GCS score, hypothermia status, depressed skull fracture, injury mechanism, age, and length of stay were not related to PTS. Most subjects included in our study population were treated with an AED after their injury, and treatment did not impact genetic relationships to PTS onset.

Despite the promising findings associated with our study, there were some limitations to consider. Limitations in medical record documentation regarding recurrent seizure occurrence limited data collection to time to first seizure. As such, we cannot conclude anything about genetic influences on recurrent late seizures. Additionally, timing of AED therapy is unclear making it difficult to determine when/how long AED therapy was given as prophylaxis or as a PTS treatment while in acute care. PTS was based on objective clinical findings reported in the medical records, with EEG data only collected in a portion of the population. Past studies have shown a high rate of subclinical and non convulsive seizures early after TBI when monitored with surface EEG electrodes (Vespa et al., 1999) and more recently, intracortical depth electrodes (Waziri et al., 2009)

Although a preliminary analysis comparing all haplotypes in relation to PTS was conducted, targeted haplotype and diplotype analysis primarily focused on those haplotypes having SNPs that were significantly associated with PTS. A larger sample size is needed to 
adequately power further assessment of all haplotypes generated. Also, our study findings are exploratory and represent only one relatively small population with TBI. To date, only a small handful of studies exist linking genetic variation to PTS risk (Wagner et al., 2010, Scher et al., 2011), and the availability of large repositories for validation and genome-wide associations studies (GWAS) are still relatively in early stages of development relative to other neurological diseases (e.g. Franke et al., 2009; Kao et al, 2011; Laje et al., 2011). Inherent study limitations often accompany candidate gene studies, including difficulties with reproducibility and generalization to other related populations. However, our study and initial findings meets many of the recommendations recently suggested for the rigorous and practical conduct of candidate gene and related types of studies, including 1) the use of only tSNPs with a minimum minor allele frequency of $<0.2,2$ ) the use of highly performing SNP assays to minimize missing data, 3) the verification of Hardy-Weinberg equilibrium for candidate SNPs 4) Odds ratios of $\sim 5-10$ demonstrating rather robust genetic effects, despite the relatively small sample size 5) data reduction prior to multivariate analysis, 6) appropriate adjustment for multiple comparisons, and 7) biologically plausible framework for results (Buxbaum et al., 2010; Newton-Cheh and Hirschhorn, 2005). Multiple comparisons adjustment using Bonferroni correction, the False Discovery Rate (FDR), or permutation testing often demand extreme statistical significance (Motsinger et al., 2007), particularly when binary outcome data are used and when associated p-values approach one, and may introduce type II error. While nominal p-values are provided, we believe this study provides an adequate biological basis for conducting confirmatory studies in appropriately sized populations that are powered for appropriate multiple comparison adjustment. The fact that different SNPs were associated with PTS in the early and sub-acute phase may imply different biologically plausible mechanisms of susceptibility given that the substrates of early vs. late PTS are likely different. Further, the requirement of rs3791878 and rs769391 on the same allele and in grouped diplotype analysis strongly suggests biological plausibility for these associations, and may suggest that these candidate gene associations reflect biological susceptibility that can be replicated in future work.

Future directions for related genetic analysis may also include in depth analysis of variability of the GABA-A receptor. GABA-A receptors are multimeric structures with several identified subunits (Lambert et al., 2003) whose variation may influence GABAergic transmission. For example, mice with point mutations altering genes coding for the a 1 subunit of the GABA-A receptor are less sensitive to anticonvulsant therapy (Rudolph et al. 1999; Crestani et al., 2000). Other knockout studies show the importance of GABA-A subunits in modulating seizure pathology (Homanics et al. 1997; Delorey et al., 1998; Sur et al., 2001; Kralic et al., 2002;). Thus, variation in genes coding for portions of the GABA-A receptor may represent a viable area of related research for determining potential risk for PTS in this population.

\subsection{CONCLUSION}

Our findings show that SNPs located in the GAD1 gene are significantly associated with the development of PTS both <1wk and 1wk-6mo post injury. The TT genotype for rs 3828275 was associated with the development of PTS <1wk. The GG genotype for rs3791878 and the AA genotype for rs 769391 were both associated with increased susceptibility to PTS $1 \mathrm{wk}-6 \mathrm{mo}$. Haplotype analysis showed that those with haplotype pairs containing 2 copies of the haplotype containing both variant risk alleles were the subjects at increased risk for PTS during this time period. Associations between rs3791878 and PTS suggest that GAD transcription, and associated GABA levels are important in the development of PTS, yet further work is required to replicate and validate these findings in other populations. These findings, along with others (Wagner et al., 2010), do provide initial support for the concept that genetic variability plays a role in PTS development. Further understanding of how 
genetic variability affects PTS susceptibility may allow us to stratify patients for therapy based on risk and maximize outcomes based on our ability to tailor treatments for this population.

\section{Acknowledgments}

This work was supported, in part, by R01HD048162 and DOD W81XWH-07-1-0701 to AKW, NIH R01NR008424, and DOD W81XWH-07-1-0701 to YPC. Thanks to the Brain Trauma Research Center for assistance with some pieces of data collection 5P01NS030318-16. Thanks to Sandra Deslouche for support with genotyping, the subjects and their families for their generous participation.

\section{References}

Allen NJ, Karadottir R, Attwell D. Reversal or reduction of glutamate and GABA transport in CNS pathology and therapy. Pflügers Arch. 2004; 449(2):132-142. [PubMed: 15338308]

Anderson GD, Temkin NR, Dikmen SS, Diaz-Arrastia R, Machamer JE, Farhrenbruch C, Miller JW, Sadrzadeh SM. Haptoglobin phenotype and apolipoprotein E polymorphism: relationship to posttraumatic seizures and neuropsychological functioning after traumatic brain injury. Epilepsy Behav. 2009; 16(3):501-506. [PubMed: 19766540]

Asada H, Kawamura Y, Maruyama K, Kume H, Ding RG, Kanbara N, Kuzume H, Sanbo M, Yagi T, Obata K. Cleft palate and decreased brain gamma-aminobutyric acid in mice lacking the $67-\mathrm{kDa}$ isoform of glutamic acid decarboxylase. Proc Natl Acad Sci U S A. 1997; 94(12):6496-6499. [PubMed: 9177246]

Bao YH, Bramlett HM, Atkins CM, Truettner JS, Lotocki G, Alonso OF, Dietrich WD. Post-traumatic seizures exacerbate histopathological damage after fluid-percussion brain injury. J Neurotrauma. 2011; 28(1):35-42. [PubMed: 20836615]

Benjamini Y, Drai D, Elmer G, Kafkafi N, Golani I. Controlling the false discovery rate in behavior genetics research. Behav Brain Res. 2001; 125:279-284. [PubMed: 11682119]

Brain Trauma Foundation, American Association of Neurological Surgeons, Congress of Neurological Surgeons. Guidelines for the management of severe traumatic brain injury. J Neurotrauma. 2007; 24(Suppl 1):S1-S106.

Bu DF, Erlander MG, Hitz BC, Tillakaretne NJ, Kaufman DL, Kaufman DL, Wagner-MacPherson CB, Evans GA, Tobin AJ. Two human glutamate decarboxylases, 65-kDa GAD and 67-kDa GAD, are each encoded by a single gene. Proc Natl Acad Sci U S A. 1992; 89(6):2115-2119. [PubMed: 1549570]

Bu DF, Tobin AJ. The exon-intron organization of the genes (GAD1 and GAD2) encoding two human gluatamate decarboxylases (GAD67 and GAD65) suggest that they derive from a common ancestral GAD. Genomics. 1994; 21(1):222-228. [PubMed: 8088791]

Buxbaum JD, Baron-Cohen S, Devlin B. Genetics in psychiatry: common variant association studies. Mol Autism. Mar 25.2010 1(1):6. [PubMed: 20678248]

Cavalleri GL, Walley NM, Soranzo N, Mulley J, Doherty CP, Kapoor A, Depondt C, Lynch JM, Scheffer IE, Heils A, Gehrmann A, Kinirons P, Gandhi S, Satishchandra P, Wood NW, Anand A, Sander T, Berkovic SF, Delanty N, Goldstein DB, Sisodiya SM. A multicenter study of BRD2 as a risk factor for juvenile myoclonic epilepsy. Epilepsia. 2007; 48(4):706-712. [PubMed: 17437413]

Chen JWY, Wasterlain CG. Status epilepticus: pathophysiology and management in adults. Lancet. 2006; 5(3):246-256.

Covic M, Karaca E, Lie DC. Epigenetic regulation of neurogenesis in the adult hippocampus. Heredity (Edinb). Jul; 2010 105(1):122-34. [PubMed: 20332807]

Crestani F, Martin JR, Möhler H, Rudolph U. Mechanism of action of the hypnotic zolpidem in vivo. Br J Pharmacol. 2000; 131(7):1251-1254. [PubMed: 11090095]

dbSNP. Short Genetic Variations. National Center for Biotechnology Information. http:// www.ncbi.nlm.nih.gov/projects/SNP

Delorey TM, Handforth A, Anagnostaras SG, Homanics GE, Minassian BA, Asatourian A, Fanselow MS, Delgado-Escueta A, Ellison GD, Olser RW. Mice Lacking the beta3 subunit of the GABA A 
receptor have the epilepsy phenotype and many of the behavioral characteristics of Angelman Syndrome. J Neurosci. 1998; 18(20):8505-8514. [PubMed: 9763493]

Diaz-Arrastia R, Gong Y, Fair S, Scott KD, Garcia MC, Carlile MC, Agostini MA, Van Ness PC. Increased risk of late posttraumatic seizures associated with inheritance of APOE epsilon4 allele. Arch Neurol. 2003; 60(6):818-822. [PubMed: 12810485]

Du J, Duan S, Wang H, Chen W, Zhao X, Zhang A, Wang L, Xuan J, Yu L, Wu S, Tang W, Li X, Li H, Feng G, Xing Q, He L. Comprehensive analysis of polymorphisms throughout GAD1 gene: a family-based association study in schizophrenia. J Neural Transm. 2008; 115(3):513-519. [PubMed: 18335162]

Ebid AH, Ahmed MM, Mohammed SA. Therapeutic drug monitoring and clinical outcomes in epileptic Egyptian patients: a gene polymorphism perspective study. Ther Drug Monit. 2007; 29(3):305-312. [PubMed: 17529887]

Ellenberger C, Mevissen M, Doherr M, Scholtysik G, Jaggy A. Inhibitory and excitatory neurotransmitters in the cerebrospinal fluid of epileptic dogs. Am J Vet Res. 2004; 65(8):11081113. [PubMed: 15334845]

Englander J, Bushnik T, Duong TT, Cifu DX, Zafonte R, Wright J, Hughes R, Bergman W. Analyzing risk factors for late posttraumatic seizures: a prospective, multicenter investigation. Arch Phys Med Rehabil. 2003; 84:365-373. [PubMed: 12638104]

Franke B, Neale BM, Faraone SV. Genome-wide association studies in ADHD. Hum Genet. Jul; 2009 126(1):13-50. [PubMed: 19384554]

Gao WM, Chadha MS, Kline AE, Clark RS, Kochanek PM, Dixon CE, Jenkins LW. Immunohistochemical analysis of histone $\mathrm{H} 3$ acetylation and methylation--evidence for altered epigenetic signaling following traumatic brain injury in immature rats. Brain Res. Jan 27; 2006 1070(1):31-4. [PubMed: 16406269]

Haltiner AM, Temkin NR, Dikmen SS. Risk of seizure recurrence after the first late posttraumatic seizure. Arch Phys Med Rehabil. 1997; 78(8):835-840. [PubMed: 9344302]

Hasegawa D, Matsuki N, Fujita M, Ono K, Orima H. Kinetics of glutamate and gamma-aminobutyric acid in cerebrospinal fluid in a canine model of complex partial status epilepticus induced by kainic acid. J Vet Med Sci. 2004; 66(12):1555-1559. [PubMed: 15644607]

Hauser WA, Annegers JF, Kurland LT. Prevalence of epilepsy in Rochester, Minnesota: 1940-1980. Epilepsia. 1991; 32:429-445. [PubMed: 1868801]

Homanics GE, DeLorey TM, Firestone LL, Quinlan JJ, Handforth A, Harrison NL, Krasowski MD, Rick CE, Korpi ER, Makela R, Brilliant MH, Hagiwara N, Ferguson C, Snyder K, Olsen RW. Mice devoid of $\gamma$-aminobutyrate type A receptor $\beta 3$ subunit have epilepsy, cleft palate, and hypersensitive behavior. Proc Natl Acad Sci U S A. 1997; 94(8):4143-4148. [PubMed: 9108119]

Hung CC, Tai JJ, Lin CJ, Lee MJ, Liou HH. Complex haplotypic effects of the ABCB1 gene on epilepsy treatment response. Pharmacogenomics. 2005; 6(4):411-417. [PubMed: 16004559]

Hsu CC, Davis KM, Jin H, Foos T, Floor E, Chen W, Tyburski JB, Yang CY, Schloss JV, Wu JY. Association of L-glutamic acid decarboxylase to the $70-\mathrm{kDa}$ heat shock protein as a potential anchoring mechanism to snaptic vesicles. J Biol Chem. 2000; 275:20822-20828. [PubMed: 10781586]

International HapMap Project. National Center for Biotechnology Information. viewed February2008, http://hapmap.ncbi.nlm.gov/

Jamali S, Salzmann A, Perroud N, Ponsole-Lenfant M, Cillario J, Roll P, Roeckel-Trevisiol N, Crespel A, Balzar J, Schlachter K, Gruber-Sedlmayr U, Pataraia E, Baumgartner C, Zimprich A, Zimprich F, Malafosse A, Szepetowski P. Functional variant in complement C3 gene promoter and genetic susceptibility to temporal lobe epilepsy and febrile seizures. PLoS One. 2010; 5(9):pii, e12740.

Kanthan R, Shuaib A. Clinical evaluation of extracellular amino acids in severe head trauma by intracerebral in vivo microdialysis. J Neurol Neurosurg Psychiatry. 1995; 59:326-327. [PubMed: 7673969]

Kao CF, Fang YS, Zhao Z, Kuo PH. Prioritization and evaluation of depression candidate genes by combining multidimensional data resources. PLoS One. Apr 6.2011 6(4):e18696. [PubMed: 21494644] 
Kash SF, Tecott LH, Hodge C, Baekkeskov S. Increased anxiety and altered responses to anxiolytics in mice deficient in the 65-kDa isoform of glutamic acid decarboxylase. Proc Natl Acad Sci U S A. 1999; 96(4):1698-1703. [PubMed: 9990087]

Kralic JE, Korpi ER, O’Buckley TK, Homanics GE, Morrow AL. Molecular and pharmacological characterization of GABA(A) receptor alpha1 subunit knockout mice. J Pharmacol Exp Ther. 2002; 302(3):1037-1045. [PubMed: 12183661]

Kuo PH, Kalsi G, Prescott CA, Hodgkinson CA, Goldman D, Alexander J, van den Oord EJ, Chen X, Sullivan PF, Patterson DG, Walsh D, Kendler KS, Riley BP. Associations of glutamate decarboxylase genes with initial sensitivity and age-at-onset of alcohol dependence in the Irish affected Sib Pair Study of Alcohol Dependence. Drug Alcohol Depend. 2009; 101:80-87. [PubMed: 19111404]

Kwan P, Baum L, Wong V, Ng PW, Lui CH, Sin NC, Hui AC, Yu E, Wong LK. Association between ABCB1 C3435T polymorphism and drug-resistant epilepsy in Han Chinese. Epilepsy Behav. 2007; 11(1):112-117. [PubMed: 17521963]

Laje G, McMahon FJ. Genome-wide association studies of antidepressant outcome: a brief review. Prog Neuropsychopharmacol Biol Psychiatry. Aug 15; 2011 35(7):1553-7. [PubMed: 21115088]

Lambert JJ, Belelli D, Peden DR, Vardy AW, Peters JA. Neurosteroid modulation of GABAA receptors. Prog Neurobiol. 2003; 71(1):67-80. [PubMed: 14611869]

Lin CM, Lin JW, Chen YC, Shen HH, Wei L, Yeh YS, Chiang YH, Shih R, Chiu PL, Hung KS, Yang LY, Chiu WT. Hyaluronic acid inhibits the glial scar formation after brain damage with tissue loss in rats. Surg Neurol. 2009; 72(Suppl 2):S50-S54. [PubMed: 19944826]

Liu SY, Han XM, Yan YY, Sun BJ, Chang Y. Quality of life and its influencing factors in patients with post-traumatic epilepsy. Chin J Traumatol. 2011; 14(2):100-103. [PubMed: 21453576]

Meldrum BS. GABAergic mechanisms in the pathogenesis and treatment of epilepsy. Br J Clin Pharmacol. 1989; 27:3S-11S. [PubMed: 2667605]

Miller MA, Conley Y, Scanlon JM, Ren D, Ilyas Kamboh M, Niyonkuru C, Wagner AK. APOE genetic associations with seizure development after severe traumatic brain injury. Brain Inj. 2010; 24(12):1468-1477. [PubMed: 20961174]

Miller SA, Dykes DD, Polesky HF. A simple salting out procedure for extracting DNA from human nucleated cells. Nucleic Acids Res. 1988; 16:1215. [PubMed: 3344216]

Motsinger AA, Haas DW, Hulgan T, Ritchie MD. Human genomic association studies: a primer for the infectious diseases specialist. J Infect Dis. 2007; 195(12):1737-44. [PubMed: 17492588]

Muir JK, Lobner D, Monyer H, Choi DW. GABAA receptor activation attenuates excitotoxicity but exacerbates oxygen-glucose deprivation-induced neuronal injury in vitro. J Cereb Blood Flow Metab. 1996; 16(6):1211-1218. [PubMed: 8898693]

Nathan B, Bao J, Hsu CC, Yarom M, Deupree DL, Lee YH, Tang XW, Kuo CY, Burghen GA, Wu JY. An integral membrane protein form of brain L-glutamate decarboxylase: purification, characterization and its relationship to insulin-dependent diabetes mellitus. Brain Res. 1994a; 642(1-2):297-302. [PubMed: 8032892]

Nathan B, Hus CC, Bao J, Wu R, Wu JY. Purification and characterization of a novel form of brain Lgluatamate decarboxylase: A Ca(2+)-dependent peripheral membrane protein. J Biol Chem. 1994b; 269:7249-7254. [PubMed: 8125937]

Neese SL, Sherill LK, Tan AA, Roosevelt RW, Browning RA, Smith DC, Duke A, Clough RW. Vagus nerve stimulation may protect GABAergic neurons following traumatic brain injury in rats: An immunocytochemical study. Brain Res. 2007; 1128(1):157-163. [PubMed: 17125748]

Newton-Cheh C, Hirschhorn JN. Genetic association studies of complex traits: design and analysis issues. Mutat Res. Jun 3; 2005 573(1-2):54-69. 2005. [PubMed: 15829237]

Nilsson P, Hillered L, Pontén U, Ungerstedt U. Changes in cortical extracellular levels of energyrelated metabolites and amino acids following concussive brain injury in rats. J Cereb Blood Flow Metab. 1990; 10(5):631-637. [PubMed: 2384536]

O'Dell DM, Gibson CJ, Wilson MS, DeFord SM, Hamm RJ. Positive and negative modulation of the GABA(A) receptor and outcome after traumatic brain injury in rats. Brain Res. 2000; 861(2):325332. [PubMed: 10760494] 
Online Mendelian Inheritance in Man. Johns Hopkins University; 2011. viewed 29 September 2011, http://www.omim.org

Palmer AM, Marion DW, Botscheller ML, Swedlow PE, Styren SD, DeKosky ST. Traumatic brain injury-induced excitotoxicity assessed in a controlled cortical impact model. J Neurochem. 1993; 61(6):2015-2024. [PubMed: 7504079]

Patel AB, De Graaf RA, Martin DL, Battaglioli G, Behar KL. Evidence that GAD65 mediates increased GABA synthesis during intense neuronal activity in vivo. J Neurochem. 2006; 97(2): 385-396. [PubMed: 16539672]

Raymont V, Salazar AM, Lipsky R, Goldman D, Tasick G, Grafman J. Correlates of posttraumatic epilepsy 35 years following combat brain injury. Neurology. 2010; 75(3):224-229. [PubMed: 20644150]

Rootsweb. Social Security Death Index (SSDI). Ancestry.com, http://ssdi.rootsweb.ancestry.com

Rudolph U, Crestani F, Benke D, Bru I, Benson JA, Fritschy JM, Martin JR, Bluethmann H, Mohler $\mathrm{H}$. Benzodiazepine actions mediated by specific gamma-aminobutyric acid (A) receptor subtypes. Nature. 1999; 401:796-800. [PubMed: 10548105]

Ruegg J, Swedenborg E, Wahlstrom D, Escande A, Balaguer P, Pettersson K, Pongratz I. The transcription factor aryl hydrocarbon receptor nuclear translocator functions as an estrogen receptor beta-selective coactivator, and its recruitment to alternative pathways mediates antiestrogenic effects of dioxin. Mol Endocrinol. 2008; 22(2):304-316. [PubMed: 17991765]

Ruppel RA, Kochanek PM, Adelson PD, Rose ME, Wisniewski SR, Bell MJ, Clark RS, Marion DW, Graham SH. Excitatory amino acid concentrations in ventricular cerebrospinal fluid after severe traumatic brain injury in infants and children: the role of child abuse. J Pediatr. 2001; 138(1):1825. [PubMed: 11148507]

Scher AI, Wu H, Tsao JW, Blom HJ, Feit P, Nevin RL, Schwab KA. MTHFR C677T Genotype As a Risk Factor for Epilepsy Including Post-Traumatic Epilepsy in a Representative Military Cohort. J Neurotrauma. 2011; 28(9):1739-1745. [PubMed: 21787169]

Schwarzer C, Sperk G. Hippocampal granule cells express glutamic acid decarboxylase-67 after limbic seizures in the rat. Neuroscience. 1995; 69(3):705-709. [PubMed: 8596641]

Soghomonian JJ, Martin DL. Two isoforms of glutamate decarboxylase: why? Trends Pharmacol Sci. 1998; 19(12):500-505. [PubMed: 9871412]

Sperk G, Schwarzer C, Heilman J, Furtinger S, Reimer RJ, Edwards RH, Nelson N. Expression of plasma membrane GABA transporters but not of the vesicular GABA transporter in dentate granule cells after kainic acid seizures. Hippocampus. 2003; 13(7):806-815. [PubMed: 14620876]

Sperk G, Wieselthaler-Hölzl A, Pirker S, Tasan R, Strasser SS, Drexel M, Pifl C, Marschalek J, Ortler M, Trinka E, Heitmair-Wietzorrek K, Ciofi P, Feucht M, Baumgartner C, Czech T. Glutamate Decarboxylase67 is Expressed in Hippocampal Mossy Fibers of Temporal Lobe Epilepsy Patients. Hippocampus. 2011 Epub ahead of print.

Stephens M, Nicholas J, Donnelly P. A new statistical method for haplotype reconstruction from population data. Am J Hum Genet. 2001; 68(4):978-989. [PubMed: 11254454]

Sur C, Wafford KA, Reynolds DS, Hadingham KL, Bromidge F, Macaulay A, Collinson N, O'Meara G, Howell O, Newman R, Myers J, Atack JR, Dawson GR, McKernan RM, Whiting PJ, Rosahl TW. Loss of the major GABA(A) receptor subtype in the brain is not lethal in mice. J Neurosci. 2001; 21(10):3409-3418. [PubMed: 11331371]

Swartz BE, Houser CR, Tomiyasu U, Walsh GO, DeSalles A, Rich JR, Delgado-Escueta A. Hippocampal cell loss in posttraumatic human epilepsy. Epilepsia. 2006; 47(8):1373-1382. [PubMed: 16922884]

Sweatt JD. Experience-dependent epigenetic modifications in the central nervous system. Biol Psychiatry. Feb 1; 2009 65(3):191-7. [PubMed: 19006788]

Temkin NR, Dikmen SS, Wilensky AJ, Keihm J, Chabal S, Winn HR. A randomized, double-blind study of phenytoin for the prevention of post-traumatic seizures. N Engl J Med. 1990; 323(8):497502. [PubMed: 2115976]

Temkin NR. Risk factors for posttraumatic seizures in adults. Epilepsia. 2003; 44(Suppl 10):18-20. [PubMed: 14511390] 
Treiman DM. GABAergic mechanisms in epilepsy. Epilepsia. 2001; 42(Suppl 3):8-12. [PubMed: 11520315]

Vespa PM, Nuwer MR, Nenov V, Ronne-Engstrom E, Hovda DA, Bergsneider M, Kelly DF, Martin NA, Becker DP. Increased incidence and impact of nonconvulsive and convulsive seizures after traumatic brain injury as detected by continuous electroencephalographic monitoring. J Neurosurg. 1999; 91:750-760. [PubMed: 10541231]

Wagner AK, Fabio A, Puccio AM, Hirschberg R, Li W, Zafont RD, Marion DW. Gender associations with cerebrospinal fluid gluatamate and lactate/pyruvate levels after severe traumatic brain injury. Crit Care Med. 2005; 33(2):407-413. [PubMed: 15699846]

Wagner AK, Miller MA, Scanlon J, Ren D, Kochanek PM, Conley YP. Adenosine A1 receptor gene variants associated with post-traumatic seizures after severe TBI. Epilepsy Res. 2010; 90(3):259272. [PubMed: 20609566]

Waziri A, Claassen J, Stuart RM, Arif H, Schmidt JM, Mayer SA, Badjatia N, Kull LL, Connolly ES, Emerson RG, Hirsch LJ. Intracortical electroencephalography in acute brain injury. Ann Neurol. Sep; 2009 66(3):366-77. [PubMed: 19798724]

Wiedemayer H, Triesch K, Schäfer H, Stolke D. Early seizures following non-penetrating traumatic brain injury in adults: risk factors and clinical significance. Brain Inj. 2002; 16(4):323-330. [PubMed: 11953003]

Yablon SA. Postraumatic seizures. Arch Phys Med Rehabil. 1993; 74(9):983-1001. [PubMed: 8379848]

Yablon SA, Dostrow VG. Post-traumatic seizures and epilepsy. Physical Medicine and Rehabilitation: State of the Art Reviews. 2001; 15:301-326.

Yoshida H, Nadanaka S, Sato R, Mori K. XBP1 is critical to protect cells from endoplasmic reticulum stress: evidence from Site-2 protease-deficient Chinese hamster ovary cells. Cell Struct Funct. 2006; 31(2):117-125. [PubMed: 17110785]

Young GB, Jordan KG, Doig GS. An assessment of nonconvulsive seizures in the intensive care unit using continuous EEG monitoring: an investigation of variables associated with mortality. Neurology. 1996; 47(1):83-89. [PubMed: 8710130]

Zhang ZY, Zhang Z, Fauser U, Schluesener HJ. Global hypomethylation defines a sub-population of reactive microglia/macrophages in experimental traumatic brain injury. Neurosci Lett. Dec 11; 2007 429(1):1-6. [PubMed: 17996371] 


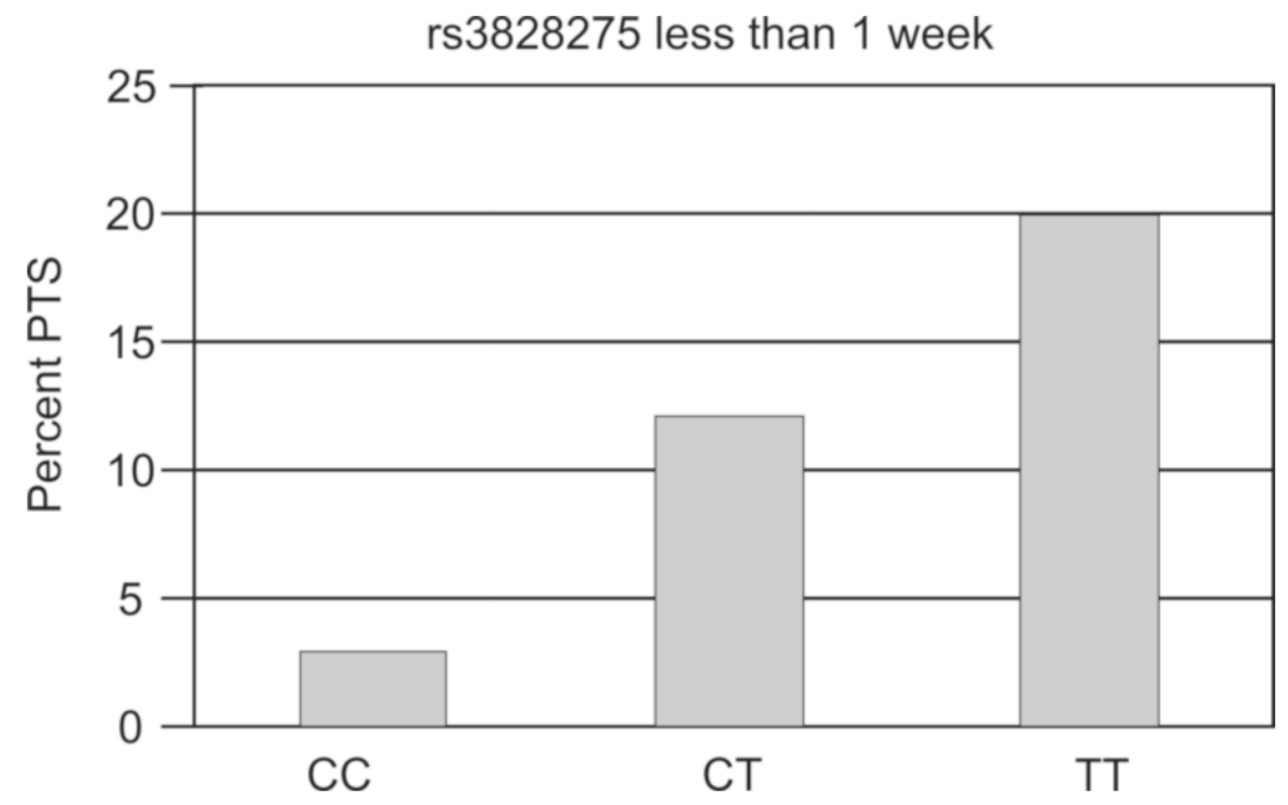

Figure 1. SNP Associations for PTS < 1 wk

Rs3828275 genotype was associated with lower PTS $<1 \mathrm{wk}(\mathrm{p}=0.014)$ vs. CT or TT. Population sizes by genotype $\mathrm{CC}=67, \mathrm{CT}=74, \mathrm{TT}=35$. 

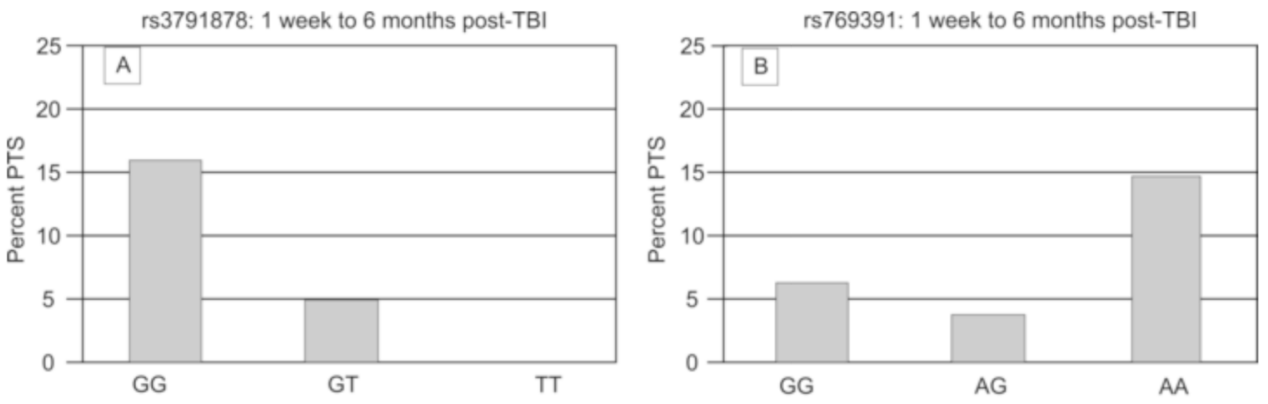

Multi-variant Analysis rs3791978 and rs769391: 1 week to 6 months post-TB|

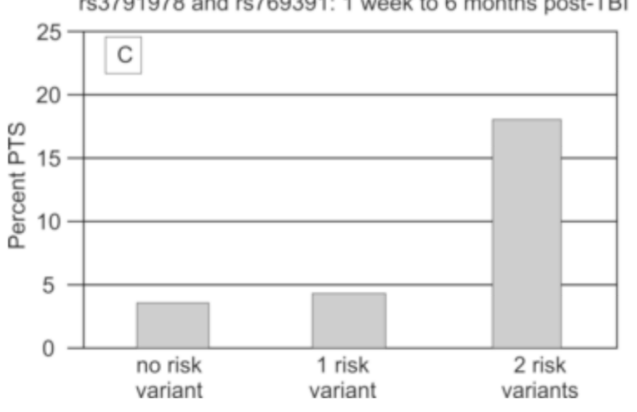

Figure 2. SNP Associations with PTS 1 wk-6 mo post-TBI

(A) rs3791878 associated with PTS in the $1 \mathrm{wk}-6$ mo post-TBI period ( $\mathrm{p}=0.05)$; population sizes by genotype $\mathrm{GG}=75, \mathrm{GT}=60, \mathrm{TT}=18$. (B) rs769391 associated with PTS in the 1 wk-6 mo post-TBI period ( $\mathrm{p}=0.094$ ) (population sizes by genotype $\mathrm{GG}=16, \mathrm{AG}=54, \mathrm{AA}=89$ ). (C) Number of risk variants associated with PTS in the $1 \mathrm{wk}-6$ mo post-TBI period $(\mathrm{p}=0.019)$; population sizes by number of risk genotypes zero $=58$, one $=24$, two $=67$. 


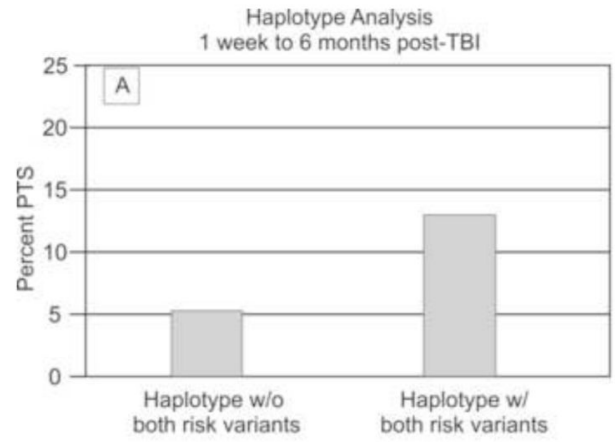

Grouped Diplotype Analysis

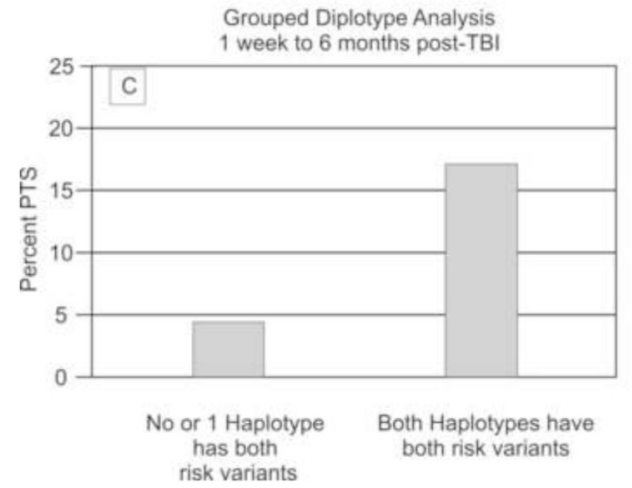

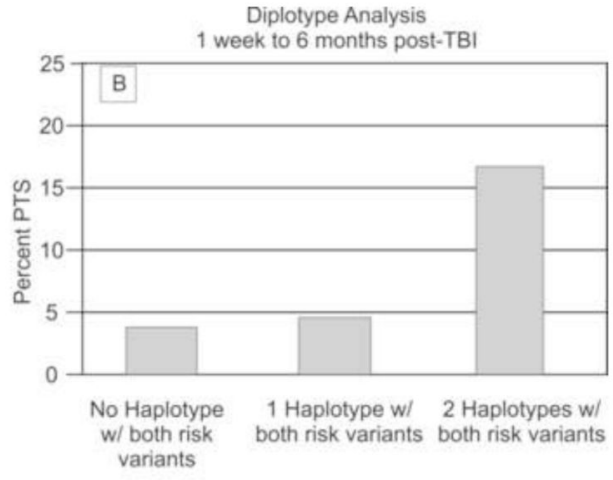

Diplotype Analysis week to 6 months post-TBi variants

Figure 3. Haplotype and Diplotype Associations with PTS 1 wk-6 mo post-TBI

(A) Haplotypes with both risk variants associated with PTS $1 \mathrm{wk}-6 \mathrm{mo}$ post-TBI $(\mathrm{p}=0.033)$; population sizes by number of variants without both=119 with both=207. (B) Two haplotypes with both risk variants associated with PTS 1 wk- 6 mo post-TBI $(p=0.038)$, population sizes by number of haplotypes with both risk variants zero $=26$ one $=66$ two $=71$. (C) Two haplotypes with both risk variants associated with PTS $1 \mathrm{wk}-6$ mo post-TBI $(\mathrm{p}=0.015)$; population sizes by number of haplotypes with both risk variants: zero or one $=92$, two $=71$. 


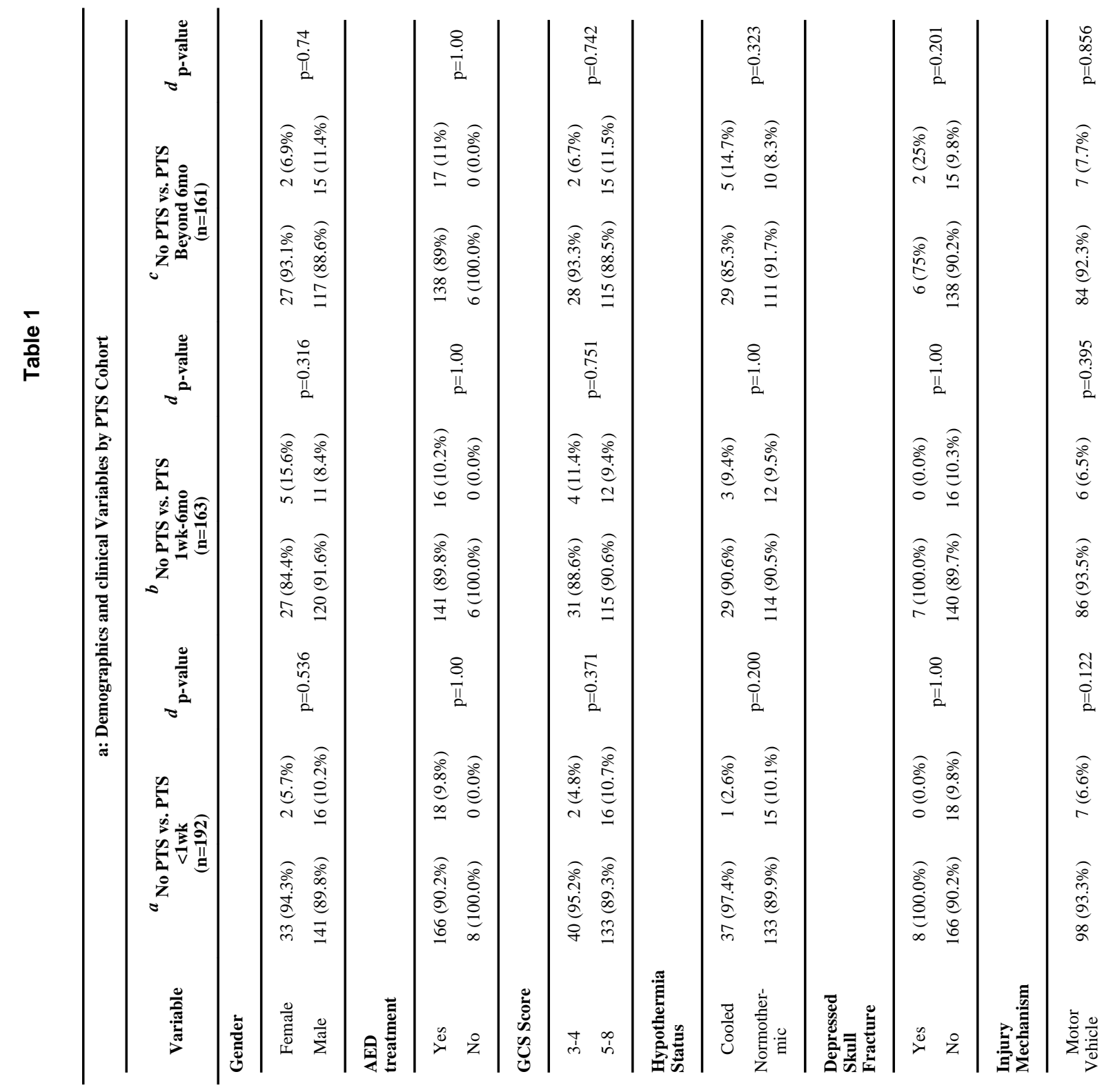




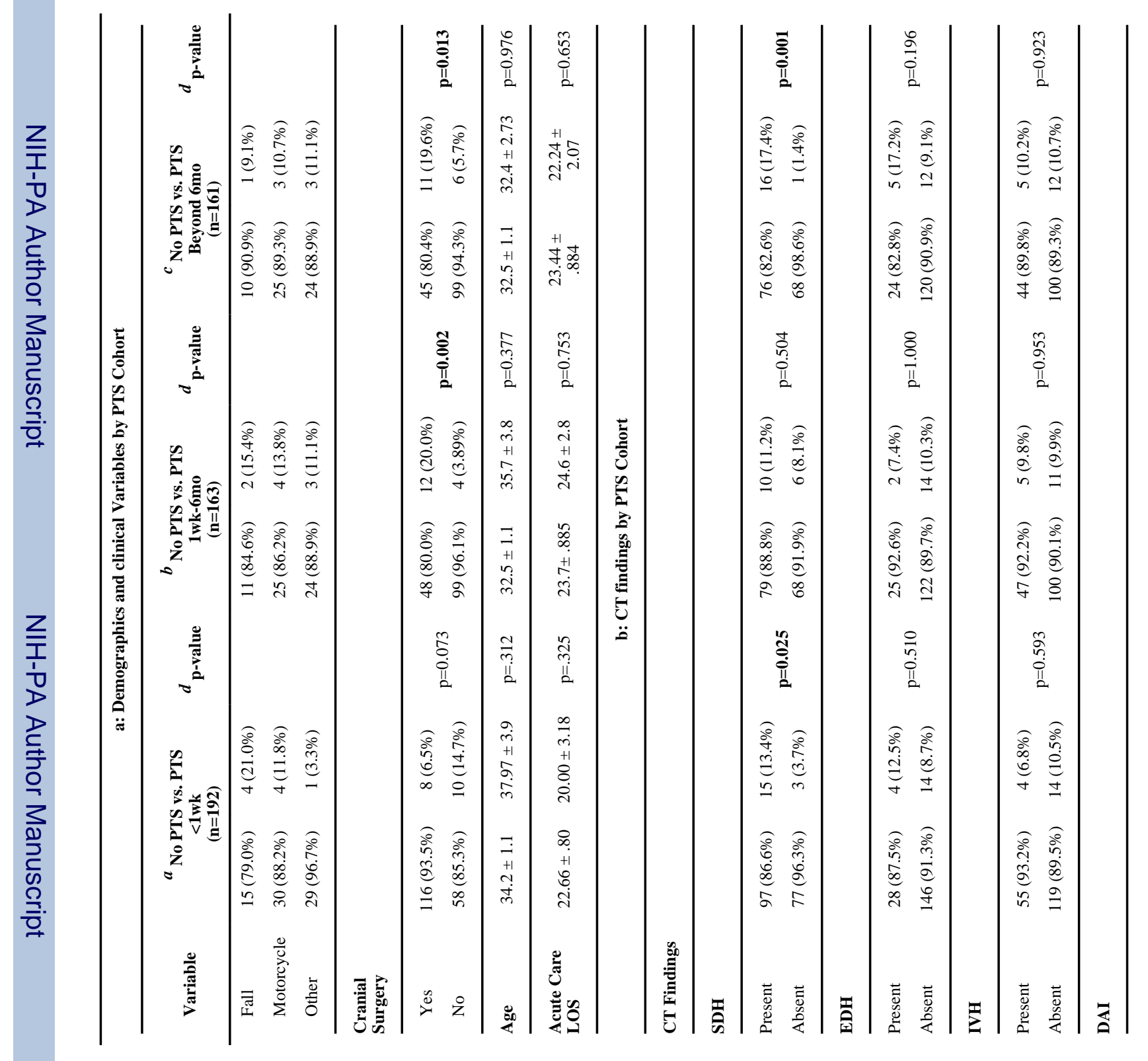

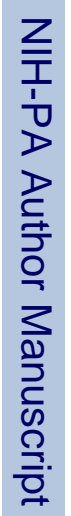




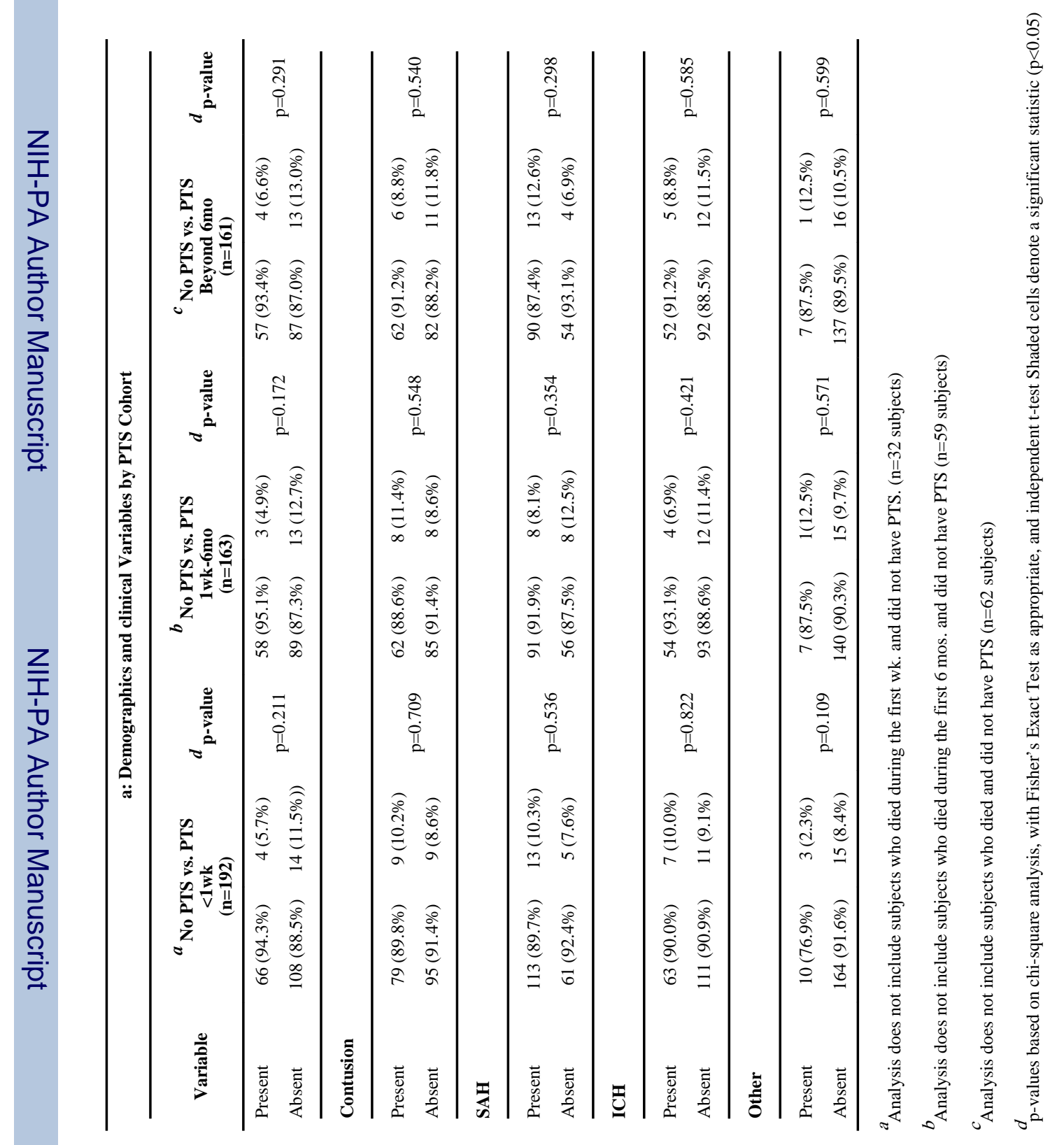

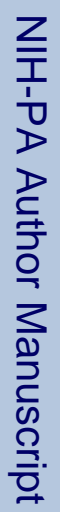




\section{Table 3}

Multivariate rs3828275 PTS <1 week

\begin{tabular}{cccc}
\hline rs3828275 & Odds Ratio & $\begin{array}{c}\text { Confidence } \\
\text { Interval }\end{array}$ & p-value \\
\hline Age & 1.004 & $0.972-1.037$ & 0.8138 \\
Gender & 1.517 & $0.305-7.576$ & 0.6102 \\
SDH & 2.711 & $0.680-10.801$ & 0.1574 \\
GCS & 1.898 & $0.388-9.259$ & 0.4292 \\
Brain Surgery & 1.862 & $0.629-5.516$ & 0.2617 \\
$\begin{array}{c}\text { Genotype } \\
\text { (CC vs.CT+TT) }\end{array}$ & 5.601 & $\mathbf{1 . 2 1 1 - 2 5 . 9 0 3}$ & $\mathbf{0 . 0 2 7 5}$ \\
\hline
\end{tabular}

Shaded cells denote a significant statistic $(\mathrm{p}<0.05)$ 


\section{Table 4}

\begin{tabular}{cccc}
\hline a: Multivariate rs3791878 PTS 1week - 6months \\
\hline rs3791878 & $\begin{array}{c}\text { Odds } \\
\text { Ratio }\end{array}$ & $\begin{array}{c}\text { Confidence } \\
\text { Interval }\end{array}$ & p-value \\
\hline Age & 1.002 & $0.961-1.044$ & 0.9307 \\
Gender & 2.692 & $0.747-9.707$ & 0.1302 \\
GCS & 1.062 & $0.248-4.552$ & 0.9355 \\
Brain Surgery & 5.191 & $1.488-18.114$ & $\mathbf{0 . 0 0 9 8}$ \\
$\begin{array}{c}\text { Genotype } \\
\text { (GG vs GT or TT) }\end{array}$ & 4.892 & $1.244-19.246$ & $\mathbf{0 . 0 2 3 1}$ \\
\hline \begin{tabular}{c} 
b: Multivariate rs769391 PTS 1week- 6months \\
\hline Age
\end{tabular} & 1.011 & $0.972-1.051$ & 0.5909 \\
Gender & 2.402 & $0.689-8.375$ & 0.1689 \\
GCS & 1.520 & $0.402-5.739$ & 0.5369 \\
Brain Surgery & 5.442 & $1.614-18.349$ & $\mathbf{0 . 0 0 6 3}$ \\
$\begin{array}{c}\text { Genotype } \\
\text { (AA vs. AG or GG) }\end{array}$ & 3.747 & $0.952-14.748$ & $\mathbf{0 . 0 5 8 9}$ \\
\hline
\end{tabular}

Shaded cells denote a significant statistic $(p<0.05)$ 
Table 5

Multi-SNP Multivariate PTS 1week - 6months

\begin{tabular}{cccc}
\hline Risk variant & $\begin{array}{c}\text { Odds } \\
\text { Ratio }\end{array}$ & Confidence Interval & p-value \\
\hline Age & 1.004 & $0.963-1.046$ & 0.8689 \\
Gender & 3.073 & $0.823-11.476$ & 0.0949 \\
GCS & 0.971 & $0.223-4.233$ & 0.9692 \\
Brain Surgery & 4.752 & $1.346-16.782$ & 0.0155 \\
Risk Variant 1vs0 & 1.308 & $0.106-16.152$ & 0.8340 \\
Risk Variant 2vs1 & 5.021 & $0.564-44.6987$ & 0.1481 \\
Risk Variant 2vs0 & 6.568 & $1.285-33.580$ & $\mathbf{0 . 0 2 3 8}$ \\
\hline $\begin{array}{l}\text { Risk Variant } \\
\text { (overall) }\end{array}$ & & & $\mathbf{0 . 0 4 2}$ \\
\hline
\end{tabular}

Shaded cells denote a significant statistic $(\mathrm{p}<0.05)$ 